\title{
Comparative study of imaging and histology of sacroiliac joint in normal rats based on IVIM-DWI and DCE-MRI
}

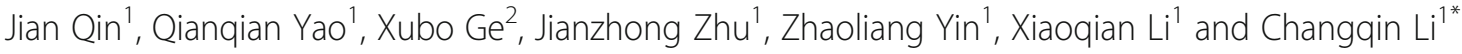

\begin{abstract}
Background: Currently, few studies have described the relationship between functional MRI findings and histology of normal sacroiliac joint (SIJ). Besides, due to the difficulties in access to SIJ, authentic animal models are important in providing opportunities for quantitative parameter extraction on imaging.

Aims: This study aimed at exploring the parameters of Intravoxel Incoherent Motion Diffusion-Weighted Imaging (IVIM-DWI) and Dynamic Contrast-Enhanced Magnetic Resonance Imaging (DCE-MRI) and comparing them with the histology of the SIJ in normal rats with different ages.

Methods: A total of thirty 7-week-old male Wistar rats were included in the study. The parameters of IVIM-DWI and DCE-MRI in the bone marrow and the joint space of SIJ were measured at 8, 13, 18, 23, 28, and 33 weeks. The histological analysis of the SIJ was examined using light microscopy. One-way ANOVA was used for statistical analysis.

Results: The D values in the sacral and iliac bone marrow of normal rats decreased with an increase in age. One-way ANOVA analysis indicated a significant difference in $D$ values in different age groups $(P<0.005)$. The normal values of $D^{*}, \mathrm{f}$, Fenh (\%), Senh (\%/s) in the sacral bone marrow, the iliac bone marrow, and the joint space in SIJ of normal rats were obtained. The results showed that in the six groups of rats of different ages, the histology of the SIJ surface was smooth and clear, the cartilage cells were intact, and no thickening or pannus formation was observed.
\end{abstract}

Conclusions: This study obtained the IVIM-DWI and DCE-MRI parameters of the sacral and iliac bone marrow and the synovial area of the joint space in normal rats. The parameters in normal rats can be used in future research to compare to similar parameters in animal models or patients with SIJ diseases. This study serves as a guide for future research in SIJ diseases.

Keywords: Sacroiliac joint, Intravoxel incoherent motion, Dynamic contrast-enhanced MRI

\section{Background}

The SIJ is an auricular shaped joint known to transfer weight and forces between the lumbar spine and lower limbs. The auricular joint surface connects the sacral and the iliac bones and it is surrounded by strong ligaments [1, 2]. Considering its functional ability, the SIJ has limited

\footnotetext{
* Correspondence: sdlichangqin@163.com

'Department of Radiology, The Second Affiliated Hospital of Shandong First Medical University, No. 366 Taishan Street, Taian City 271000, Shandong, China

Full list of author information is available at the end of the article
}

motion capabilities. Therefore, the main function of SIJ is to maintain body stability. Sacroiliitis is considered to be an important criterion for the diagnosis and classification of ankylosing spondylitis [3]. To understand the pathologies arising in the SIJ, it is very important to understand the normal anatomy, histology, and imaging characteristics of the normal SIJ. Previous studies have focused on some parts of the descriptive anatomy, diagnosis, and treatment of SIJ pathologies $[4,5]$. Other studies have also emerged on the biomechanics of the SIJ, in terms of the structural relationships of the joint with surrounding tissues [6, 7]. In

(C) The Author(s). 2020 Open Access This article is licensed under a Creative Commons Attribution 4.0 International License, which permits use, sharing, adaptation, distribution and reproduction in any medium or format, as long as you give appropriate credit to the original author(s) and the source, provide a link to the Creative Commons licence, and indicate if changes were made. The images or other third party material in this article are included in the article's Creative Commons licence, unless indicated otherwise in a credit line to the material. If material is not included in the article's Creative Commons licence and your intended use is not permitted by statutory regulation or exceeds the permitted use, you will need to obtain permission directly from the copyright holder. To view a copy of this licence, visit http://creativecommons.org/licenses/by/4.0/ The Creative Commons Public Domain Dedication waiver (http://creativecommons.org/publicdomain/zero/1.0/) applies to the data made available in this article, unless otherwise stated in a credit line to the data. 
recent years, modern imaging technologies have been widely studied for early diagnosis of arthritis [8]. However, there is a lack of comparative studies on imaging analysis of the normal SIJ. Some scholars have performed pathological and related MR examinations of the SIJ using the male corpse [9]. However, these studies do not reflect the physiological condition of a normal and abnormal SIJ in the living state and cannot be used to extract quantitative imaging parameters. Therefore, few studies have described the relationship between functional MRI findings and histology of normal SIJ. Besides, due to the difficulties in access to SIJ, authentic animal models are important in providing opportunities for quantitative parameter extraction on imaging.

In this study, we hypothesized that there is a relationship between the IVIM-DWI and DCE-MRI parameters and the histological findings of normal SIJ. Therefore, in this study, MR parameters of IVIM-DWI and DCE-MRI were measured in rats of different age groups and compared with histological findings.

\section{Methods}

Research objects

Thirty male Wistar rats were obtained from Experimental Animal breeding Co., Ltd. (China, Jinan). The rats were 7 weeks old and weighed 170-200 g. All rats were acclimatized in a Specific Pathogen Free (SPF) environment for 1 week before the experiment. At 8, 13, 18, 23, 28, and 33 weeks, 5 rats were randomly selected for MRI examination under anesthesia (3 $\mathrm{ml}$ of Urethane intraperitoneal injection, Shanghai Shanpu Chemical Co., Ltd), then euthanized and sent for histological analysis. A $0.2 \mathrm{~g} / \mathrm{mL}$ solution of Urethane was prepared using saline (total of $10 \mathrm{ml} / \mathrm{kg}$ ) with intraperitoneal injection. The study was approved by the Institutional Animal Care and Use Committee of Shandong First Medical University and was performed in accordance with the National Institutes of Health guidelines for the use of laboratory animals.

\section{MR imaging techniques}

All MR imaging was performed using a 3.0-T MR (GE discovery MR750) and utilizing a matched eight-channel animal coil (Wankang Medical Technology Co., Ltd., China). Four standard MR imaging sequences were performed. (A) Axial T2 fat-saturated (FS) images [echo time (TE)/repetition time (TR), $96.1 \mathrm{~ms} / 3000 \mathrm{~ms}$; echo train length,16]; (B) Coronal T1 FS fast spin-echo (FSE) (TE/TR, $13.5 \mathrm{~ms} / 500 \mathrm{~ms}$; echo train length, 3); (C) IVIM-DWI: repetition time/echo time (TR/ TE) $4000 / 66.8 \mathrm{~ms}$, slice thickness $3.0 \mathrm{~mm}$, matrix $64 \times 64$, FOV $140 \mathrm{~mm} \times 112 \mathrm{~mm}$, spatial resolution $3.8 \mathrm{~mm}^{2}$, a total of 12 b-values were used: $10,20,30,50,80,100,200,300$, 600, 800, 1000, $1500 \mathrm{~s} / \mathrm{mm}^{2}$. (D) DCE-MRI: fat-saturated contrast-enhanced T1 images with the liver acquisition with volume acceleration (LAVA) sequence, repetition time/echo time (TR/TE) 5.6/1.9 ms, slice thickness $2.0 \mathrm{~mm}$, matrix
$128 \times 128$, FOV $200 \mathrm{~mm} \times 160 \mathrm{~mm}$. A total of 80 phases were acquired, with a spatial resolution of $2.0 \mathrm{~mm} 2.1 \mathrm{ml}$ of gadopentetate dimeglumine contrast agent (BeiLu Pharmaceutical Co., Ltd., Beijing, China) was administered intravenously (tail vein) at a rate of $0.1 \mathrm{ml} / \mathrm{s}$, followed by a $2 \mathrm{ml}$ saline (0.9\%, Shandong Qidu Pharmaceutical Co., Ltd) flush by hand. The concentration of gadopentetate dimeglumine was $0.5 \mathrm{~g} / \mathrm{ml}$. After the acquisition of seven baseline dynamic scans, 960 images were collected in total with 80 phases for approximately $5 \mathrm{~min}$ of scanning; the function tool software of GE MR Advantage Workstation 4.6 was used to perform the measurements of DCE-MRI and IVIM-DWI.

\section{Image analysis}

\section{Analysis of IVIM parameters}

The DWI signal follows the biexponential model to calculate the signal attenuation IVIM, as [10]:

$$
\begin{aligned}
\mathrm{S}(\mathrm{b}) / \mathrm{S}_{0}= & (1-\mathrm{f}) \exp (-\mathrm{bD}) \\
& +\mathrm{f} \exp [-\mathrm{b} \times(\mathrm{D} *+\text { Dblood })]
\end{aligned}
$$

Where $\mathrm{Sb}$ is the signal intensity in the pixel with diffusion gradient $b, S_{0}$ is the signal intensity without diffusion gradient, $\mathrm{D}\left(\times 10^{-4} \mathrm{~mm}^{2} / \mathrm{s}\right)$ is the water diffusion coefficient in the tissue, $\mathrm{f}$ is the perfusion fraction related to microcirculation (flowing blood fraction) and $\mathrm{D}^{*}(\mathrm{x}$ $10^{-4} \mathrm{~mm}^{2} / \mathrm{s}$ ) is the pseudo-diffusion coefficient which represents perfusion-related diffusion.

\section{Analysis of DCE-MRI parameters}

For DCE-MRI parameter analysis, all data were quantitatively analyzed using image processing software. This was calculated by manually drawing different regions of interest (ROIs), to obtain the time-intensity curves (TICs).

Enhancement factor Fenh $(\%)=\left(\mathrm{SI}_{\max }-\mathrm{SI}_{0}\right) \times 100 \% / \mathrm{SI}_{0}$; Enhancement slope Senh $(\% / s)=\left(\mathrm{SI}_{\max }-\mathrm{SI}_{0}\right) 100 /\left(\mathrm{SI}_{0} \times \mathrm{T}_{\max }\right)$;

where $\mathrm{SI}_{0}$ (baseline signal intensity before contrast injection) approaches the $\mathrm{SI}_{\max }$ (maximum signal intensity) exponentially in time. $\mathrm{SI}_{\max }$ is determined as the maximum SI during the DCE-MRI examination and $\mathrm{T}_{\max }$ is the time point of $\mathrm{SI}_{\max }$.

\section{Data analysis}

The original images were processed using the Advantage Workstation (ADW 4.6 version, GE, US) and postprocessed by Functool workstation. Two observers with 15 years and 20 years of experience in MRI were blinded to the information and they individually measured the resulting parameter maps. Any arising disagreements of both radiologists were resolved by consensus. All data were measured 3 times and the average is taken to 


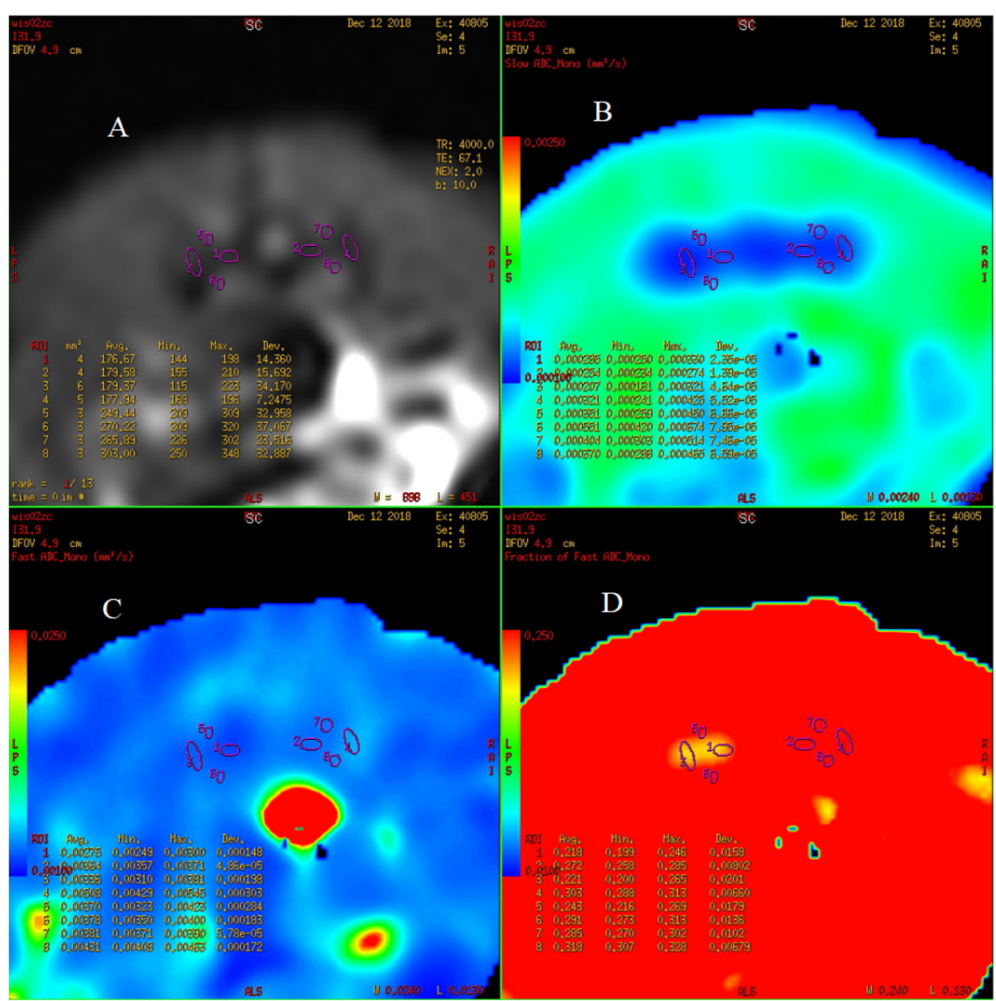

Fig. 1 IVIM-DWI images of the SIJ in normal rats, (a-d) Axial T2-weighted FS image, D, D*, f

reduce bias caused by measurement error. On the IVIMDWI and DCE-MRI series, an ovoid region of interest (ROI) was placed within the bilateral sacral or iliac bone marrow. The ROI of the joint space was placed at the lower third of the cartilaginous portion of the SIJ [11] and all ROIs were $2-4 \mathrm{~mm}^{2}$. The bilateral average values were obtained and care was taken to avoid the cortex, venous plexus, ligaments, or any imaging-related artifacts (Figs. 1, 2, 3).

\section{Histological assessment}

After MR examination, the rats were weighed and each rat was euthanized with $1 \%$ pentobarbital (Sigma company) $100 \mathrm{mg} / \mathrm{kg}$ intraperitoneal injection. When the heartbeats were not detected for $5 \mathrm{~min}$, SIJ samples were removed, fixed in $10 \%$ formalin ( $200 \mathrm{ml}$ per sample) for 1-2 days, acid-decalcified with $10 \%$ methanoic acid for 1 week, embedded in paraffin, cut after dehydration in graded ethanol (75\% ethanol 15 s, $85 \%$ ethanol 10s, $95 \%$

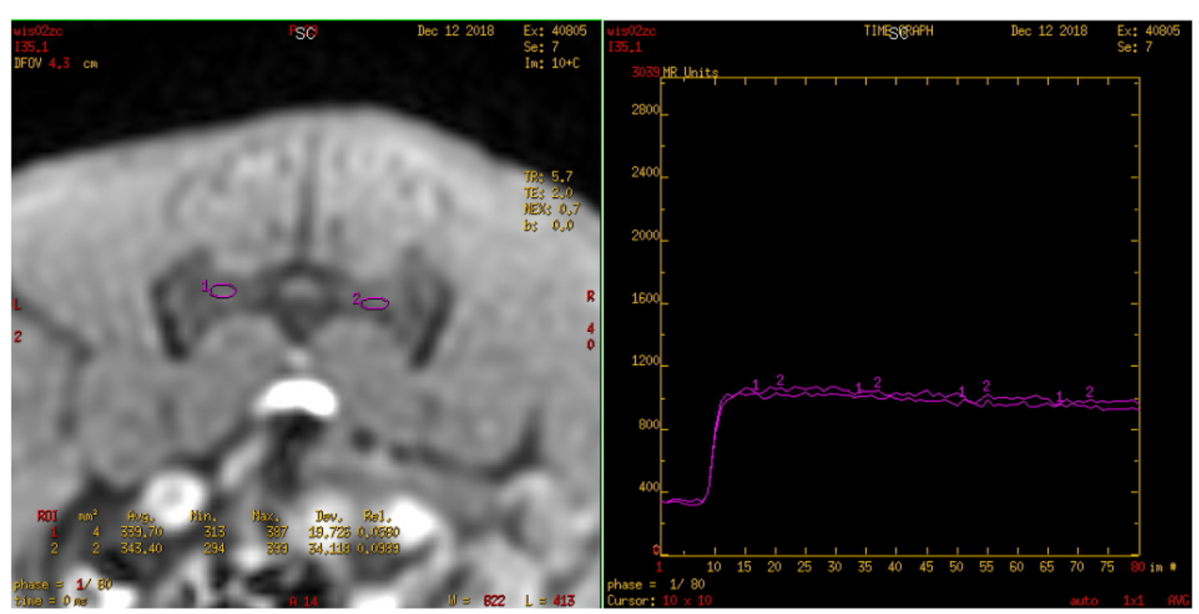

Fig. 2 The TIC of the bilateral sacral bone marrow of the 28-week rat is a type I curve (rapid rise/steep slope and slow drop type) 


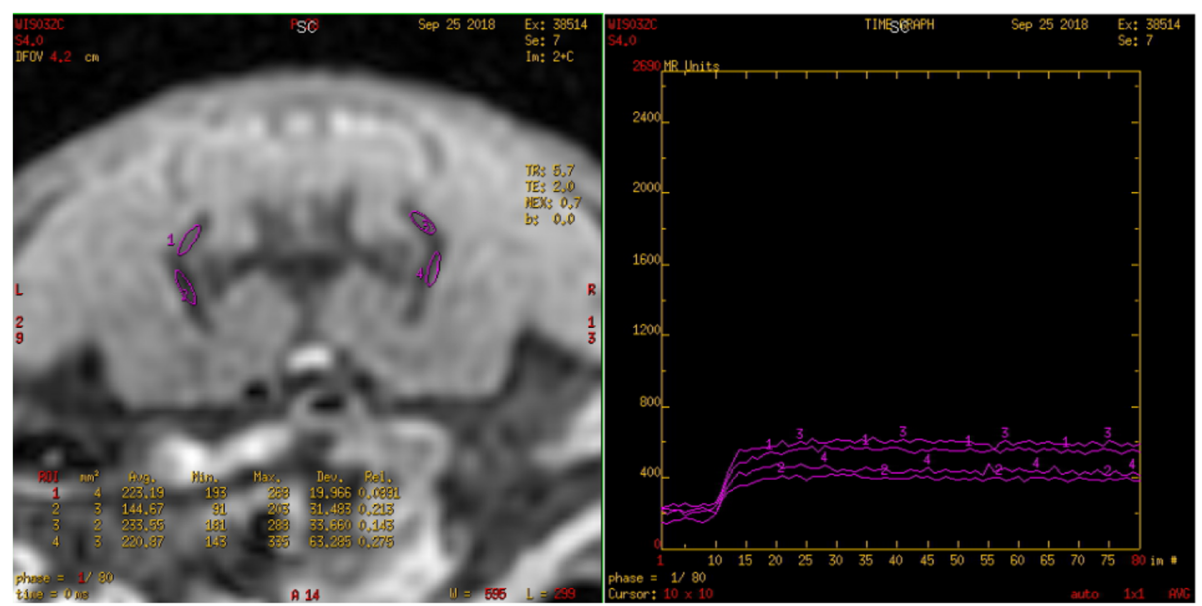

Fig. 3 The TIC of the bilateral iliac bone marrow in the 23-week rat is a type II curve (platform/plateau type)

ethanol 10s, absolute ethanol $1 \mathrm{~min}$, absolute ethanol 1 min,) and stained with hematoxylin (8 $\mathrm{min})$ and eosin (2 min). The histological changes of the SIJ were observed under a microscope (MODEL BX53F, OLYMPUS, Tokyo, Japan).

\section{Statistical analysis}

SPSS Statistics version 19.0 was used to perform statistical analysis. The test for homogeneity of variances was performed using Levene's tests. All the parameter values were compared by one-way ANOVA. The measured parameters were expressed as means \pm standard deviation (SD). $P$ values $<0.05$ were considered statistically significant.

\section{Results}

\section{Performance of Wistar rats}

Over the entire study period, there was no statistically significant difference in appearance (including paw, hair, tail, spine, etc.) among the five groups of male Wistar rats of different ages.

Table 1 IVIM parameters among different age groups in the bone marrow of the sacrum

\begin{tabular}{llll}
\hline- & $D\left(\times 10^{-4} \mathrm{~mm}^{2} / \mathrm{s}\right)$ & $D^{*}\left(\times 10^{-4} \mathrm{~mm}^{2} / \mathrm{s}\right)$ & $\mathrm{f}(\%)$ \\
\hline 8 weeks & $4.84 \pm 0.43$ & $28.99 \pm 4.80$ & $24.45 \pm 4.84$ \\
13 weeks & $4.63 \pm 0.40$ & $27.37 \pm 3.87$ & $26.83 \pm 3.97$ \\
18 weeks & $4.76 \pm 0.61$ & $27.76 \pm 3.18$ & $25.54 \pm 4.87$ \\
23 weeks & $4.34 \pm 0.63$ & $26.50 \pm 2.89$ & $24.81 \pm 2.89$ \\
28 weeks & $3.89 \pm 0.34$ & $26.88 \pm 4.19$ & $24.63 \pm 3.26$ \\
33 weeks & $3.67 \pm 0.37$ & $25.66 \pm 2.80$ & $24.36 \pm 3.54$ \\
$F$ & 26.673 & 1.581 & 1.152 \\
$P$ & $0.000^{*}$ & 0.157 & 0.336
\end{tabular}

The values of $D, D^{*}$, and $f$ are presented as means \pm standard deviation in the bone marrow of the sacrum. * indicates a significant difference
Results of the various parameters of the SIJ in normal rats from the IVIM-DWI sequence

The values of $\mathrm{D}\left(\times 10^{-4} \mathrm{~mm}^{2} / \mathrm{s}\right)$ in the sacrum and the iliac bone marrow of normal rats in different age groups decreased with an increase in age. One-way ANOVA analysis indicated a significant difference in $D$ values among different age groups $(P=0.000)$ (Table $1-2)$. Besides, there was no statistically significant difference among the $D, D *$ and $f$ values of the joint space in SIJ in different age groups $(P>0.05)$. The normal values of corresponding parameters are shown in Table 3. IVIMDWI images of the SIJ in normal rats are shown in Fig. 1.

\section{Results of the various parameters of SIJ in normal rats from DCE-MRI sequence}

The values of Fenh (\%) and Senh (\%/s) in the sacral and iliac bone marrow and the joint space in the SIJ were not significantly different from an increase in age $(P>$ 0.05). The normal values of corresponding parameters are shown in Table 4. Based on observation and analysis

Table 2 IVIM parameters among different age groups in the bone marrow of the iliac bone

\begin{tabular}{llll}
\hline- & $\mathrm{D}\left(\times 10^{-4} \mathrm{~mm}^{2} / \mathrm{s}\right)$ & $\mathrm{D}^{*}\left(\times 10^{-4} \mathrm{~mm}^{2} / \mathrm{s}\right)$ & $\mathrm{f}(\%)$ \\
\hline 8 weeks & $5.23 \pm 0.54$ & $30.41 \pm 4.80$ & $27.00 \pm 3.93$ \\
13 weeks & $4.84 \pm 0.61$ & $29.84 \pm 4.52$ & $27.35 \pm 3.64$ \\
18 weeks & $4.90 \pm 0.72$ & $30.11 \pm 4.96$ & $26.71 \pm 3.01$ \\
23 weeks & $4.73 \pm 0.70$ & $29.15 \pm 3.97$ & $25.91 \pm 2.99$ \\
28 weeks & $3.94 \pm 0.51$ & $29.31 \pm 6.16$ & $27.61 \pm 3.33$ \\
33 weeks & $3.83 \pm 0.45$ & $29.08 \pm 5.77$ & $27.48 \pm 3.04$ \\
$F$ & 19.290 & 0.189 & 0.446 \\
$P$ & $0.000^{*}$ & 0.980 & 0.847 \\
\hline
\end{tabular}

The values of $D, D^{*}$, and $f$ are presented as means \pm standard deviation in the bone marrow of the iliac bone. ${ }^{*}$ indicates a significant difference 
Table 3 Normal values of IVIM-DWI parameters in the sacral and iliac bone marrow and the joint space in the SIJ of normal rats

\begin{tabular}{llll}
\hline & sacral bone marrow & iliac bone marrow & the joint space \\
\hline $\mathrm{D}\left(\times 10^{-4} \mathrm{~mm}^{2} / \mathrm{s}\right)$ & - & - & $6.28 \pm 0.28$ \\
$D^{*}\left(\times 10^{-4} \mathrm{~mm}^{2} / \mathrm{s}\right)$ & $27.31 \pm 3.90$ & $29.62 \pm 5.14$ & $61.85 \pm 14.93$ \\
$\mathrm{f}(\%)$ & $25.21 \pm 3.79$ & $26.98 \pm 3.38$ & $19.85 \pm 3.82$ \\
\hline
\end{tabular}

The values of $D, D^{*}$, and $f$ are presented as means \pm standard deviation

of the dynamic enhancement curve, the sacral bone marrow showed a type I curve (rapid rise and slow drop, Fig. 2); the iliac bone marrow and the joint space in the SIJ of normal rats showed a type II curve (platform, Fig. 3).

\section{Histological changes}

The six groups of rats with different ages had a smooth and clear SIJ surface, the cartilage cells were intact, the synovium was normal, and no thickening or pannus formation was observed (Fig. 4).

\section{Discussion}

The SIJ participates in stabilizing the body movements and helps to maintain balance. The complex anatomical structure and deep position of the SIJ make it difficult to conduct general examinations. Therefore, the diagnostic evaluation of the SIJ is mainly based on medical imaging modalities. Plain X-ray examination can only show the general shape of the SIJ, and the value of X-ray in clinical diagnosis, treatment, and follow-up is insufficient. CT clearly shows the osteoarticular surfaces and subarticular trabecular bone, however, the display of articular cartilage and bone marrow changes is insufficient [12]. MRI can clearly show the bone marrow cavity, the articular cartilage, and the surrounding soft tissue. Bone Marrow Edema (BME) is relatively easy to depict on short tau inversion recovery (STIR) images and has a high sensitivity in the diagnosis of SpA. However, the extent of the lesion cannot be quantified [13, 14]. Therefore, the application of new MRI scanning technologies like IVIM-DWI and DCE-MRI can gradually compensate for these shortcomings.

Due to the difficulties in the histological analysis of SIJ, authentic animal models are important in providing opportunities for quantitative parameter extraction on imaging. In this study, the rat model of sacroiliac

Table 4 Normal values of DCE-MRI parameters in the sacral and iliac bone marrow and the joint space in the SIJ of normal rats

\begin{tabular}{llll}
\hline & sacral bone marrow & iliac bone marrow & the joint space \\
\hline Fenh (\%) & $205.26 \pm 21.04$ & $202.87 \pm 40.56$ & $194.19 \pm 24.41$ \\
Senh(\%/s) & $3.93 \pm 1.22$ & $3.17 \pm 1.34$ & $2.51 \pm 0.41$ \\
\hline
\end{tabular}

The values of Fenh (\%), Senh (\%/s) are presented as means \pm standard deviation arthritis was successfully established by using bovine proteoglycan combined with complete/incomplete Freund's adjuvant. The results showed that synovitis was an early pathological manifestation of sacroiliac arthritis, and these findings were consistent with the findings in other studies conducted on human subjects [15]. As a control group, our study lays a foundation for the pathogenesis of ankylosing spondylitis in rats and provides opportunities to investigate their histology in relationship to human disease.

The apparent diffusion coefficient (ADC) is the most commonly used metric in the mono-exponential model (MEM) of DWI, which does not consider the influence of the microcirculation of blood in capillaries, thus leading to an inaccurate description of the diffusion process [16]. Besides, two main aspects affect the measured diffusion signals in living tissues, the motion of water molecules, and the perfusion of the tissue microvasculature. In 1986, Le Bihan et al. described a new imaging technique referred to as IVIM using multi b-value DWI with a bi-exponential curve fitting [10]. This technique is sensitive not only to molecular diffusion in tissues but also to random blood flow in capillaries. The technique also provides related analytical parameters represented by diffusion-related parameters D (pure molecular diffusion) and perfusion-related parameters including $\mathrm{D}^{*}$ (pseudo-diffusion coefficient) and $\mathrm{f}$ (perfusion fraction). Semi-quantitative DCE-MRI using a generalized kinetic model allows for estimation of tissue perfusion and capillary permeability, which involves not only exchange dynamics between extra-vascular/extra-cellular space, but also some other factors, such as the pattern of blood delivery, blood vessel density, vascular permeability, and distribution of contrast agent in lesions [17]. Numerous studies have demonstrated the efficiency of IVIM-DWI and DCE-MRI parameters in prostate cancer [18], breast cancer [19], and liver fibrosis [20]. However, very few studies have been reported on SIJ.

In this study, the results showed that the D-values of the sacral and iliac bone marrow decreased with an increase in age and the difference was found to be statistically significant $(P=0.000)$. However, $D^{*}$ and $f$ values did not show statistically significant differences in the groups. The reason could have been that the main components of the bone marrow cavity of the normal sacrum and ilium are the bone trabeculae and bone 


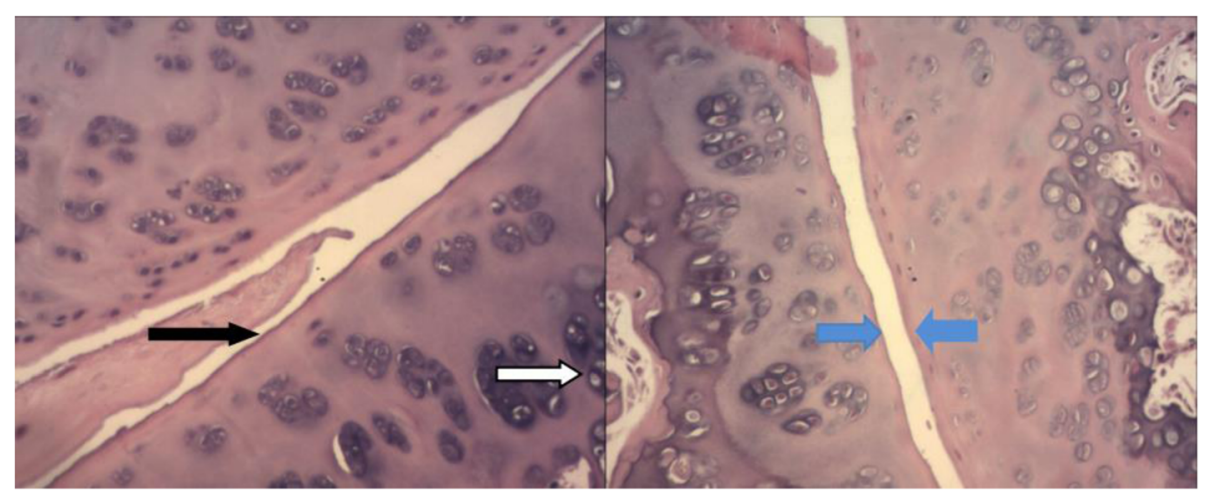

Fig. 4 Clearly showing the synovium (black arrow), chondrocytes (white arrow), sacroiliac surface (blue arrow). The magnification is $200 \times$

marrow. The main components of bone trabeculae are minerals such as calcium salts and almost no water molecules can be found, therefore, little to no effect on MR images is expected. The bone marrow is divided into two types: the yellow and red bone marrow. The bone marrow cavity in a newborn is filled with the red bone marrow. With increasing age, part of the red bone marrow is replaced with the yellow bone marrow. The red bone marrow contains different stages of red blood cells, white blood cells, platelets, and the cellular component contains a lot of water. However, the main component of the yellow bone marrow is fat, hence, the ratio of water molecules contained in the two different types of bone marrow is different. Water content and different states of water molecules can affect the image characteristics and corresponding parameters [21]. Rats aged 8 weeks to 32 weeks old correspond to human beings aged 12 to 20 years old, and the bone marrow in the SIJ in this age has begun to transform from red bone marrow to yellow bone marrow. At the same time, the content of free water molecules in the bone marrow decreases gradually. Therefore, the $\mathrm{D}$ value reflecting the true water molecule diffusion also decreases with an increase in age. However, there was no lesion, no inflammatory reaction, or necrosis. Therefore, there was no significant difference in $D$ *and $f$ values with the increase of age.

In this study, the initial signal intensity $\left(\mathrm{SI}_{0}\right)$, the maximum signal intensity $\left(\mathrm{SI}_{\max }\right)$, and the peak time $\left(\mathrm{T}_{\max }\right)$ were obtained using semi-quantitative analysis. The enhancement slope and factor were obtained by the signal time-intensity curve (TIC) of the region of interest in normal rats. There were 180 TIC curves of the SIJ bone marrow region (sacral, iliac) and of the synovial area of the joint space. On the sacral side, a type I curve was observed (with a rapid rise and slow drop). In the synovial area and at the iliac side, a type II curve was observed (with a rapid rise and a platform). There were no significant differences in Fenh (\%) and Senh (\%/s) between the sacral and iliac bone marrow with increasing age.
The results showed that in the six groups of rats of different ages, the histology of the SIJ surface was smooth and clear, the cartilage cells were intact, and no thickening or pannus formation was observed.

The use of IVIM-DWI and DCE-MRI as functional imaging modalities in normal rats to investigate the histology of the normal bone marrow and SIJ is an unmet need in the field of SIJ research. Therefore, the parameters in normal rats obtained in this study can be used in future research to compare with parameters in human patients with sacroiliac joint diseases. Differences in quantitative parameters are of great importance to understand the physiology and pathophysiology of normal versus diseased SIJs. The anatomopathological features of the normal SIJs in rats indicate the absence of sacroiliac joint diseases. Therefore, this study can guide future research in SIJ diseases.

This study was funded by the Natural Science of Shandong Provincial Foundation, China (No.ZR2017MH105), and Academic Promotion Programme of Shandong First Medical University (No.2019QL017).

\section{Limitations}

The sample size in the study is relatively small. The correlation between diagnostic imaging and histopathology was not studied in detail. Besides, the spatial resolution of the IVIM-DWI scan was low. Furthermore, the ADC value was not calculated along with the $\mathrm{D}$ value to make our data more easily comparable with other studies.

\section{Conclusions}

In conclusion, histological findings, IVIM-DWI and DCE-MRI parameters of sacrum, ilium bone marrow, and synovial area of joint space in normal rats are presented in this study. These parameters can be used in future research to compare with parameters in animal models or patients with SIJ diseases. 


\section{Abbreviations}

SIJ: Sacro-lliac Joint; IVIM-DWI: Intravoxel Incoherent Imaging DiffusionWeighted Imaging; DCE-MRI: Dynamic Contrast-Enhanced Magnetic resonance imaging; ROI: Region of Interest; TIC: Time-Intensity Curve; ANOVA: Analysis of Variance

\section{Acknowledgements}

We thank Xinli Wang for the assistance in the histological assessment and Qiuling Zhang for the assistance in the animal experiments.

\section{Authors' contributions}

JQ, QQY, XBG, JZZ, ZLY, XQL and CQL designed the study. JQ and QQY performed the data analysis and carried out the histological assessment, XBG contributed to the data interpretation. ZLY, XQL and CQL supervised the project. JQ wrote the manuscript and QQY, XBG, JZZ, ZLY, XQL and CQL made contributions to its final form. All authors have read and approved the manuscript in this form.

\section{Funding}

This study was funded the Natural Science of Shandong Provincial Foundation, China (No.ZR2017MH105) and Academic Promotion Programme of Shandong First Medical University (No.2019QL017)

\section{Availability of data and materials}

The datasets used and/or analyzed during the current study are available from the corresponding author on reasonable request.

\section{Ethics approval and consent to participate}

The study was approved by the Institutional Animal Care and Use Committee and was performed in accordance with the National Institutes of Health guidelines for the use of laboratory animals.

\section{Consent for publication}

Not applicable.

\section{Competing interests}

The authors declare that they have no competing interests.

\section{Author details}

${ }^{1}$ Department of Radiology, The Second Affiliated Hospital of Shandong First Medical University, No. 366 Taishan Street, Taian City 271000, Shandong, China. 'Department of Radiology, The Fourth People's Hospital of Taian, Taian 271000, Shandong, China.

Received: 12 November 2019 Accepted: 6 July 2020

Published online: 20 July 2020

\section{References}

1. Stallmeyer MJ, Ortiz AO. Facet blocks and sacroiliac joint injections. Tech Vasc Interv Radiol. 2002;5:201-6.

2. Van Hauwermeiren L, Verstraete M, Stouthandel MEJ, et al. Joint coordinate system for biomechanical analysis of the sacroiliac joint. J Orthop Res. 2019; 37:1101-9.

3. Rudwaleit M, Metter A, Listing J, et al. Inflammatory back pain in ankylosing spondylitis: a reassessment of the clinical history for application as classification and diagnostic criteria. Arthritis Rheum. 2006;54:569-78.

4. Cohen SP, Chen Y, Neufeld NJ. Sacroiliac joint pain: a comprehensive review of epidemiology, diagnosis and treatment. Expert Rev Neurother. 2013;13: 99-116

5. Vleeming A, Schuenke MD, Masi AT, et al. The sacroiliac joint: an overview of its anatomy, function and potential clinical implications. J Anat. 2012;221: 537-67.

6. Barker PJ, Hapuarachchi KS, Ross JA, et al. Anatomy and biomechanics of gluteus maximus and the thoracolumbar fascia at the sacroiliac joint. Clin Anat. 2014:27:234-40.

7. Sichting F, Rossol J, Soisson O, et al. Pelvic belt effects on sacroiliac joint ligaments: a computational approach to understand thera peutic effects of pelvic belts. Pain Physician. 2014;17:43-51.

8. Maksymowych WP, Wichuk S, Dougados M, et al. MRI evidence of structural changes in the sacroiliac joints of patients with non-radiographic axial spondyloarthritis even in the absence of MRI inflammation. Arthritis Res Therapy. 2017;19:126.

9. Puhakka KB, Melsen $F$, Jurik $A G$, et al. MR imaging of the normal sacroiliac joint with correlation to histology. Skelet Radiol. 2004;33:15-28.

10. Le Bihan D, Breton E, Lallemand D, et al. MR imaging of intravoxel incoherent motions: application to diffusion and perfusion in neurologic disorders. Radiology. 1986;161:401-7.

11. Maksymowych WP, Lambert RG, Østergaard M, et al. MRI lesions in the sacroiliac joints of patients with spondyloarthritis: an update of definitions and validation by the ASAS MRI working group. Ann Rheumatic Dis. 2019; 78(11):1550-8

12. Tan S. Computed tomography in axial spondyloarthritis. Curr Opinion Rheumatol. 2018:30:334-9.

13. El Rafei M, Badr S, Lefebvre G, et al. Sacroiliac joints: anatomical variations on MR images. Eur Radiol. 2018;28:5328-37.

14. Jans L, Egund N, Eshed I, Sudoł-Szopińska I, et al. Sacroiliitis in axial Spondyloarthritis: assessing morphology and activity. Seminars in musculoskeletal radiology. 2018;22:180-8.

15. Qin J, Li J, Yang H, et al. Values of intravoxel incoherent motion diffusion weighted imaging and dynamic contrast-enhanced MRI in evaluating the activity of sacroiliitis in ankylosing spondylitis of rat model. Magnetic Resonance Imaging. 2020;68:30-5.

16. Fujima N, Sakashita T, Homma A, et al. Advanced diffusion models in head and neck squamous cell carcinoma patients: goodness of fit, relationships among diffusion parameters and comparison with dynamic contrastenhanced perfusion. Magn Reson Imaging. 2017;36:16-23.

17. Kim SH, Choi MS, Kim MJ, et al. Role of semi-quantitative dynamic contrastenhanced MR imaging in characterization and grading of prostate cancer. Eur J Radiol. 2017:94:154-9.

18. Shinmoto H, Tamura C, Soga S, et al. An intravoxel incoherent motion diffusion-weighted imaging study of prostate cancer. Am J Roentgenol. 2012;199:W496-500.

19. Murata Y, Kubota K, Hamada N, et al. Diffusion-weighted magnetic resonance imaging for assessment after neoadjuvant chemotherapy in breast cancer, based on morphological concepts. Oncol Letters. 2010;1:2938.

20. Sandrasegaran $K$, Territo $P$, Elkady RM, et al. Does intravoxel incoherent motion reliably stage hepatic fibrosis, steatosis, and inflammation? Abdominal Radiol. 2018:43:600-6.

21. Winalski CS. The evolution of articular cartilage imaging and its impact on clinical practice. Skeletal Radiol. 2011:40:1197-222.

\section{Publisher's Note}

Springer Nature remains neutral with regard to jurisdictional claims in published maps and institutional affiliations.

Ready to submit your research? Choose BMC and benefit from:

- fast, convenient online submission

- thorough peer review by experienced researchers in your field

- rapid publication on acceptance

- support for research data, including large and complex data types

- gold Open Access which fosters wider collaboration and increased citations

- maximum visibility for your research: over $100 \mathrm{M}$ website views per year

At $\mathrm{BMC}$, research is always in progress.

Learn more biomedcentral.com/submission 